\title{
Editorial
}

\section{On the road: Communicating traffic}

\section{Abstract}

How do people communicate in mobile settings of interaction? How does mobility affect the way we speak? How does mobility exert influence on the manner in which talk itself is consequential for how we move in space? Recently, questions of this sort have attracted increasing attention in the human and social sciences. This Special Issue contributes to the emerging body of studies on mobility and talk by inspecting an ordinary and ubiquitous phenomenon in which communication among mobile participants is paramount: participation in traffic. This editorial presents previous work on mobility in natural settings, as carried out by interactionally oriented researchers. It also shows how the investigation into traffic participation adds new perspectives to research on language and communication.

\section{Introduction}

Turn-taking is used for the ordering of moves in games, for allocating political office, for regulating traffic at intersections, for serving customers at business establishments, and for talking in interviews, meetings, debates, ceremonies, conversations etc.

(Sacks, Schegloff and Jefferson, 1974: 696)

Investigation into spoken language can look back on a long tradition of research, which has developed into variegated and well-grounded approaches. While the analysis of empirical data - i.e. recordings of talk - has become an established practice in many approaches, the corpora on which such research is based rarely consider mobile settings of interaction. In fact, we may well speak of a 'stationary bias' that characterizes the state-of-the-art of research on talk-ininteraction. Clearly, this observation does not aim to invalidate previous research. Rather, it reveals a blatantly underinvestigated dimension of human interaction - mobility - which is consequential for how speakers talk, crucially involving other dimensions of embodied conduct, such as gaze, gesture, the manipulation of objects, etc. Spatial reference, for instance, is a simple and transparent illustration of why mobility matters to speakers. Saying 'here' to a passenger while driving a car at high speed brings about other practical problems (for both speaker and recipient) than using the same deictic while sitting with friends at the pub. Space has been a dominant dimension of linguistic research since the first contributions to the field. For more than two centuries, areal linguistics has been dealing with the spatial distribution of linguistic variation (see Auer and Schmidt, 2010 for an introduction). In this tradition, language evolution (e.g. of Indo-European languages; Bopp, 1816) was anchored in space: Schmidt's (1872) wave theory or Bartoli's (1925) theory of areal norms for language change are well known examples. At the same time, linguistic geography developed into a major field of dialectological research, with Georg Wenker's work on the Deutscher Sprachatlas (first maps in 1888) and Gilliéron and Edmont's (1902-1910) systematic work on the Atlas linguistique de la France. These studies are characterized by an 'absolute' view of space, conceptualized as a 'container' within which specific linguistic phenomena are observable (see Auer, Hilpert, Stukenbrock and Szmrecsanyi, 2013 for a discussion). In this line of research, language is shown to depend on social and geographical space, whereas how speakers use language to refer to space is not explored. Instead, this issue became a main area of interest of cognitive linguistics. In the second half of the $20^{\text {th }}$ century, cognitively oriented linguists studied how speakers express spatial relations (Vater, 1991; Pütz and Dirven, 1996; Talmy, 2000), and how these grammaticize as prepositions (such as over, on, etc.; Lakoff and Johnson, 1980; Lakoff, 1987). Within more anthropologically minded approaches, researchers 
have described different frames of reference (Senft, 1997; Levinson, 2003; Haun, Rapold, Janzen, and Levinson, 2011) speakers mobilize when locating an object in space. Finally, researchers working on interaction have highlighted how speakers design place formulations (Schegloff, 1972) based on the ways participants are socially categorized, the place at which they are currently located, and the topic or activity at hand.

With the exception of some rare pioneering articles (such as Psathas, 1976), it is only recently that researchers have started considering mobility as a relevant dimension for the analysis of talk. It is especially with regard to openings of social encounters that the analysis of mobility - and more specifically of how participants position their bodies in space - has led to insightful findings. Kendon (1977) introduced the notion of facing formation to describe how participants orient themselves vis-à-vis each other when engaging in a face-to-face encounter. Subsequent work has shown how speakers construct their utterances in ways that are sensitive to, among other things, participants' movements in space (McIlvenny, Broth and Haddington, 2009; De Stefani, 2013; Haddington, Mondada and Nevile, 2013).

In the social sciences, mobility has emerged as an important feature of interaction in public. However, it is only at the beginning of the current century that social scientists have observed a mobility turn (Urry, 2007), arisen from the observation that although mobility is a pervasive feature of human life, it had been addressed only marginally by previous research (Cresswell, 2006). Yet early studies on mobility are well known: in particular, both Goffman (1971) and Ryave and Schenkein (1974) study how people walk in public space. Goffman (1971) developed the notion of vehicular units to refer to 'shell[s] of some kind controlled [...] by a human pilot or navigator' (p. 6), and as examples he mentions e.g. submarines, open cars and pedestrians. Following the previous studies on the flow of pedestrians, Lee and Watson (1992) have focused on how pedestrians monitor each other's spatial trajectories, and Mondada (2001) on how members categorize each other in public spaces. Similarly, 'walking and talking', as well as other forms of movement in 'mobile formations' (McIlvenny, Broth and Haddington, 2014: 105), have been identified and studied by ethnomethodologists and conversation analysts as ordinary social activities. Goffman (1963: 177) observes, for instance, that speakers engaging in interaction may build up an involvement shield, which protects them from access by third parties. But ' $[\mathrm{t}]$ he involvement shield provided by a conversation is somewhat portable, because the participants can together move about a room and take their talk with them'. Such research has stimulated later studies on 'walking and talking' (Relieu, 1999; Watson, 2005; Broth and Lundström, 2013; Broth and Mondada, 2013; Mondada, 2017), 'running and talking' (Collinson, 2006), 'driving and talking' (Laurier, 2005; Haddington, 2010; see Section 2), and 'talking in the cockpit' (Nevile, 2004, 2007) - not to mention the studies by authors who have analyzed data stemming from a 'walk and talk' activity, however without specifically focusing on the interactants' mobility (e.g. Psathas, 1992). The mobility of blind pedestrians has been studied by Relieu (1994) and Due and Bierring Lange (2017). Recently, research has also focused on the use of technological resources - such as geographical maps on smartphones - for orienting in space (Laurier, Brown and McGregor, 2015; Licoppe, 2016).

This Special Issue extends prior research on mobile settings of interaction based on the methodological background of ethnomethodology and multimodal conversation analysis. It proposes a set of empirically grounded analyses of interactions taking place in mobile environments and among different types of road users (pedestrians, cyclists, car drivers, etc.).

\section{Traffic interaction}

As outlined above, mobile settings of interaction have attracted researchers working with conversation analytic methods (Haddington, Mondada and Nevile, 2013). Mondada (2012) and Goodwin and Goodwin (2012) have described the habitable car (Laurier, Brown and 
Lorimer, 2005) as a setting in which multiple courses of action take place. How navigation is formulated and negotiated in ordinary driving has been a central aspect of research (Haddington and Keisanen, 2009; Haddington, 2010, 2012, 2013; Laurier, Brown and Lorimer, 2012). Driving lessons have only recently been approached as a research topic: De Stefani and Gazin (2014) describe recurrent instructional sequences occurring in driving lessons and distinguish between navigational instructions and car control instructions. Deppermann (2015) discusses recipient design and intersubjectivity in relation to the intelligibility of instructions. Focusing on a broader range of mobile activities (driving, cycling, flying), Levin et al. (2017) analyze how corrections of mobile actions are subsequently 'unpacked' by the instructor, and Rauniomaa et al. (2018) describe how mobile tasks (related to driving, flying and skiing) are parsed into their constitutive sub-actions. Practices of coordination in traffic (beyond rule-based behavior) have been studied by Juhlin (2010) and Liberman (2013), whereas McIlvenny (2014) analyzes interaction between cyclists participating in traffic as a mobile with (Jensen, 2010).

Participants engaging in road traffic implement a variety of communicative practices. At least two participation frameworks are manifestly at work: a) interaction taking place between members of a mobile with, i.e. individuals jointly engaged in navigation (e.g. a pair of pedestrians, driver and passenger, etc.); and b) interaction between different road users. Participants in traffic have to coordinate these two different participation frameworks in response to constantly evolving, contingent traffic situations. This question has been only scarcely addressed in previous research (but see Deppermann, 2015; Broth, Cromdal and Levin, 2018). Since participants have to coordinate their actions in different yet interrelated domains, this Special Issue focuses on the following questions:

a) How do individuals who are engaged in joint mobility coordinate their actions? Joint mobility is multi-activity: individuals participating in traffic as vehicular units or as part of mobile withs coordinate talk-in-interaction with their navigational behavior (see Haddington, 2010; McIlvenny, 2014). For instance, they jointly negotiate navigational issues (Haddington and Keisanen, 2009; Haddington, 2010, 2012, 2013; Laurier, Brown and Lorimer, 2012) in addition to engaging in topical talk about everyday issues (Mondada, 2012). In other settings, such as driving lessons, participants devote a large part of their in-car interaction to the formulation and execution of instructions (De Stefani and Gazin, 2014; De Stefani, 2018; Deppermann, 2015, 2018; Gazin, 2015; Broth, Cromdal and Levin, 2017, 2018; De Stefani and Gazin, this issue, Deppermann, this issue; Broth, Cromdal and Levin, this issue). In general, a practical problem for road users consists in deciding whether and at what moment a specific navigational action is relevant and necessary - in a constantly evolving traffic situation - and how this action can be collaboratively achieved (Deppermann et al., 2018; Deppermann, this issue; Liberman, this issue; Mcllvenny, this issue; Merlino and Mondada, this issue).

b) How do road users coordinate their actions and trajectories in traffic? Road users have to coordinate their actions in order to navigate through traffic in a safe and fluent manner (Liberman, this issue). However, opportunities for coordination and the range of available semiotic means may be severely restricted (Deppermann, this issue; Laurier, this issue). Moreover, participants have to react, plan and project their actions within short temporal intervals. In order to coordinate their respective actions, traffic participants can use different semiotic means (gestures, headlight flashing, horn honking, etc.; see von Savigny, 1980; Haddington and Rauniomaa, 2014; Broth, Cromdal and Levin, 2018; De Stefani and Gazin, this issue; Laurier, this issue), but they also rely on formal (traffic code) and informal rules (Juhlin, 2010), prior experience, (semiotic) affordances of the road (traffic signs, layout of the street, etc.), and the observable actions of other traffic 
participants (Deppermann, this issue). Action coordination builds on expectations about the actions of others (Broth, Cromdal and Levin, this issue).

c) How do road users coordinate their engagement in multiple participation frameworks and how do they identify and categorize other vehicular units? Accomplishing a navigational action (e.g. crossing a road as a pedestrian, performing a turn at a junction, etc.) requires road users to carry out a set of ordered actions and to coordinate these actions with the conduct of other road users. For instance, research on in-car interaction has shown that passengers participate in the driving behavior technically carried out by the driver (Haddington and Rauniomaa, 2014): they comment on, assess and explain others' as well as their own actions, discuss the applicability of and the situated interpretation of traffic laws, anticipate future actions of others, decide on their own actions based on perceptions and interpretations of traffic events and spatial configurations, etc. (De Stefani and Gazin, this issue; McIlvenny, this issue). Moreover, passengers locally categorize other road users as, e.g., vulnerable, 'dangerous' drivers, or drivers who do not respect the traffic code (see Katz, 1999).

While they accomplish the complex coordination tasks described above, participants use talk as well as embodied resources and technological artifacts to solve the practical problem of safely navigating through space.

\section{Gains from the study of traffic for understanding language, communication and interaction}

Traffic constitutes a unique environment in which participants simultaneously have to deal with different participation frameworks that are constantly rearranged due to the road users' movement through space. Issues of multi-activity, materiality, temporality and sensitivity to space and movement are pervasive in this setting, both among road users and between members of a mobile with. These issues have become major topics in research on language and interaction in recent years (Haddington, Mondada and Nevile, 2013; Haddington, Keisanen, Mondada and Nevile, 2014; McIlvenny, Broth and Haddington, 2014; Deppermann and Günthner, 2015). They are omni-relevant in the coordination of multiple courses of action in traffic. Traffic represents a fertile setting for analyzing the ways linguistic resources are adapted to, and constitute, the ever-changing spatial, temporal, mobile, topical and pragmatic relevancies of a social setting that counts among the most important ones in contemporary societies, but that has to date largely been neglected by scholars in language and communication.

a) Language is a fundamental resource that members use to participate in traffic-related activities, such as topical talk, organizing their traffic behavior, commenting on other road users' actions, finding the way, instructing, etc. Different languages provide different linguistic resources for accomplishing these activities. In this Special Issue, we have collected contributions based on data in five languages (English, French, German, Italian and Swedish), thereby providing the possibility to identify both language-specific and action-specific practices. For instance, different grammatical formats are used to produce distinct driving instructions (Deppermann, 2018; De Stefani, 2018; Mondada, 2018). However, participants engaged in traffic rely not only on talk but also on other resources, such as gaze and gesture (Laurier, this issue; McIlvenny, this issue; Merlino and Mondada, this issue). Starting with the pioneering work by Goodwin (1979, 1980, 2017), research on multimodality in interaction has now become a core approach among studies on language-in-interaction (Deppermann, 2013; Deppermann and Streeck, 2018; Mondada, 2018). Work on the ways participants coordinate linguistic resources with 
multimodal ones, and adapt the grammatical shape of turns-at-talk to co-occurring trafficrelated phenomena, thus importantly adds to our knowledge about embodied interaction.

b) Communication is of primordial importance in traffic. The smooth flow of traffic is based on, among other things, the correct interpretation of textual and semiotic objects and features (e.g. signposts), as well as the spatial infrastructure. For instance, the configuration of the road 'instructs' (in the sense of Garfinkel 2002) road users how to move through space. Road signs provide traffic participants with instructions and information relevant to their navigational behavior. Traffic participants' resources are both provided for (e.g. the body, indicators, lights, horns) and restricted by the technical, spatial and temporal properties of communication between different means of transport, such as cars (which Goffman, 1963 described as portable shields, whereas they are iron cages for Urry, 2004), bicycles, wheelchairs, etc. The use of communicative resources is sensitive to features such as visibility, speed and proximity. All these resources are designed to be unambiguous, yet traffic participants need to make sense of them, and may treat them as problematic and in need of negotiation - e.g. because they are unable to apply information provided by a road sign to the current traffic situation, or, in driving lessons, because the formulation of a rule is not adapted to the student driver's level of competence and experience (Deppermann, 2015). Equally, road users have to learn and decide how to make their own actions projectable and comprehensible in a situated way (e.g. a pedestrian raising a hand may display his project to cross a road), so that other road users can coordinate their actions with them (Broth, Cromdal and Levin, this issue; Deppermann, this issue; Mcllvenny, this issue; Merlino and Mondada, this issue). Hence, by examining the communicative practices and the potential of road signs, traffic rules, spatial configurations and semiotic resources used by participants in actual traffic situations, we contribute new knowledge about the meaning potentials (Linell, 2009) and limits of these semiotic resources and the situated requirements and contingencies imposing on their use.

c) Interaction involves anticipating and responding to others' conduct, thereby enabling both simultaneous and sequential action coordination. As the quotation from Sacks, Schegloff and Jefferson's (1974) seminal paper at the beginning of this editorial shows, the authors address a broad range of situations in which sequential turn-taking is at stake. In the decades following its publication, scholars have focused extensively on conversations as a locus in which interactional practices and the constitution of social order are observable - hence the label conversation analysis for the approach. By analyzing interactions that take place between road users - who have highly restricted possibilities to talk to each other - this Special Issue also sheds light on the resources other than talk that traffic participants deploy when coordinating their conduct with each other. Just like the 'floor' in conversation, in many cases road space is a scarce, insufficient resource for the organization of turn-taking. Hence, road users employ further resources to coordinate with each other who goes first (Deppermann, this issue; Laurier, this issue; Liberman, this issue; Mcllvenny, this issue). By focusing on how participants coordinate interaction between road users with interaction within the mobile with, the articles in this Special Issue contribute to the study of participation frameworks of interaction and their interrelationships (De Stefani and Gazin, this issue). In addition, this issue is closely linked with phenomena of multi-activity arising from simultaneous involvements in multiple and co-occurring courses of (inter)action (Haddington, Keisanen, Mondada and Nevile, 2014).

\section{Conclusion}


Humans may participate in traffic in many different ways - not only as pedestrians, but also as individuals piloting a car, a wheelchair, a mobility scooter, a bicycle, etc. They have to cope with both the affordances and restrictions provided by their (technologically equipped) shell (Goffman, 1971) serving them as a locomotion device. And they have to communicate with other traffic participants - who may belong to the same or different kinds of vehicular units - in order to accomplish mobility in a safe and effortless manner. Safe coordination in mobility is an interactional achievement, and as such a phenomenon in which the use of language and other communicative resources has a fundamentally social purpose. As Vinkhuyzen and Cefkin (2016) have shown concerning autonomously driving cars, a major problem is their flagrant incapacity to take into account the social dimension of traffic. This Special Issue confirms that sociality and also civility are of cardinal importance for making traffic work. In so doing, it presents traffic as an exemplary phenomenon for analyzing the complexity of human communication.

\section{Die Sprache beruht auf dem Verkehr der Menschen untereinander.}

Wegener (1885: 182)

\section{References}

Auer, P., Schmidt, J. E. (Eds.), 2010. Language and Space. Berlin, De Gruyter.

Auer, P., Hilpert, M., Stukenbrock, A., Szmrecsanyi, B. (Eds.), 2013. Space in Language and Linguistics: Geographical, Interactional, and Cognitive Perspectives. Berlin, De Gruyter.

Bartoli, M. G., 1925. Introduzione alla neolinguistica: Principi, scopi, metodi. Genève, Olschki.

Bopp. F., 1816. Über das Conjugationssystem der Sanskritsprache in Vergleichung mit jenem der griechischen, lateinischen, persischen und germanischen Sprache. Frankfurt am Main, Andreäische Buchhandlung.

Broth, M., Cromdal, J., Levin, L., 2017. Starting out as a driver: Progression in instructed pedal work. In: Mäkitalo, Å., Linell, P., Säljö, R. (Eds.), Memory Practices and Learning: Interactional, Institutional and Sociocultural Perspectives. Charlotte NC, Information Age Publishers, pp. 113-143.

Broth, M., Cromdal, J., Levin, L., 2018. Showing where you're going: Instructing the accountable use of the indicator in live traffic. International Journal of Applied Linguistics.

Broth, M., Cromdal, J., Levin, L., this issue. Telling the other's side: Formulating what others think in driver training.

Broth, M., Lundström, F., 2013. A walk on the pier: Establishing relevant places in a mobile instruction. In: Haddington, P., Mondada, L., Nevile, M. (Eds.), Interaction and Mobility: Movement as Social Action. Berlin, Mouton de Gruyter, pp. 91-122.

Broth, M., Mondada, L., 2013. Walking away: The embodied achievement of activity closings in mobile interaction. Journal of Pragmatics 47, 41-58.

Collinson, J. A., 2006. Running-together. Some ethnomethodological considerations. Ethnographic Studies 8, 17-29.

Cresswell, T., 2006. On the Move: Mobility in the Modern Western World. London, Routledge.

Deppermann, A., 2015. When recipient design fails: Egocentric turn-design of instructions in driving school lessons leading to breakdowns of intersubjectivity. Gesprächsforschung/Discourse and Conversation Analysis 16, 63-101.

Deppermann, A., 2018. Instruction practices in German driving lessons: Differential uses of declaratives and imperatives. International Journal of Applied Linguistics.

Deppermann, A., this issue. Intersubjectivity and other grounds for action-coordination in an environment of restricted interaction: Coordinating with oncoming traffic when passing an obstacle.

Deppermann, A., Günthner, S. (Eds.), 2015. Temporality in Interaction. Amsterdam/Philadelphia: John Benjamins.

Deppermann, A., Laurier, E., Mondada, L. et al., 2018. Overtaking as an interactional accomplishment in live traffic. Gesprächsforschung/Discourse and Conversation Analysis 19, http://www.gespraechsforschungonline.de/2018.html.

Deppermann, A., Streeck, J. (Eds.), 2018. Time in Embodied Interaction: Synchronicity and Sequentiality of Multimodal Resources. Amsterdam/Philadelphia, John Benjamins.

De Stefani, E., 2013. Rearranging (in) space. On mobility and its relevance for the study of face-to-face interaction. In: Auer, P., Hilpert, M., Stukenbrock, A., Szmrecsanyi, B. (Eds.), Space in Language and Linguistics: Geographical, Interactional, and Cognitive Perspectives. Berlin, De Gruyter, pp. 434-463. 
De Stefani, E., 2018. Formulating direction: Navigational instructions in driving lessons. International Journal of Applied Linguistics.

De Stefani, E., Gazin, A.-D., 2014. Instructional sequences in driving lessons: Mobile participants and the temporal and sequential organization of actions. Journal of Pragmatics 65, 63-79.

De Stefani, E., Gazin, A.-D., this issue. Learning to communicate: Managing multiple strands of participation in driving lessons.

Due, B., Bierring Lange, S., 2017. The Moses effect: The spatial hierarchy and joint accomplishment of blind person navigating. Space and Culture, doi: 10.1177/1206331217734541.

Garfinkel, H., 2002. Instructions and instructed actions. In: Garfinkel, H. (Ed.), Ethnomethodology's Program. Oxford, Rowman \& Littlefield, pp. 197-218.

Gazin, A.-D., 2015. Instructional Sequences in Driving Lessons: A Conversation Analytic and Multimodal Approach to Interaction in the Mobile Car. Unpublished PhD Thesis, University of Berne (Switzerland).

Gilliéron, J., Edmont, E., 1902-1910. Atlas linguistique de la France. Paris, Champion.

Goffman, E., 1963. Behavior in Public Spaces. New York, The Free Press.

Goffman, E., 1971. Relations in Public. New York, Basic Books.

Goodwin, C., 1979. The interactive construction of a sentence in natural conversation. In: Psathas, G. (Ed.), Everyday Language: Studies in Ethnomethodology. New York, Irvington Publishers, pp. 97-121.

Goodwin, C., 1980. Restarts, pauses, and the achievement of a state of mutual gaze at turn-beginning. Sociological Inquiry 50 (3/4), 272-302.

Goodwin, C., 2017. Co-operative Action. Cambridge, Cambridge University Press.

Goodwin, C., Goodwin, M. H., 2012. Car talk: Integrating, texts, bodies, and changing landscapes. Semiotica $191(1 / 4), 257-286$.

Haddington, P., 2010. Turn-taking for turntaking: Mobility, time, and action in the sequential organization of junction negotiations in cars. Research on Language and Social Interaction 43 (4), 372-400.

Haddington, P., 2012. Movement in action: Initiating social navigation in cars. Semiotica 191 (1/4), 137-167.

Haddington, P., 2013. Projecting mobility: Passengers directing drivers at junctions. In: Haddington, P., Mondada, L., Nevile, M. (Eds.), Interaction and Mobility: Language and the Body in Motion. Berlin, De Gruyter, pp. 179-209.

Haddington, P., this issue. Leave-taking as multiactivity: Coordinating conversational closings with driving cars.

Haddington, P., Keisanen, T., 2009. Location, mobility and the body as resources in selecting a route. Journal of Pragmatics 41, 1938-1961.

Haddington, P., Keisanen, T., Mondada, L. Nevile, N. (Eds.), 2014. Multiactivity in Social Interaction: Beyond Multitasking. Amsterdam/Philadelphia, John Benjamins.

Haddington, P., Mondada, L., Nevile, M. (Eds.), 2013. Interaction and Mobility: Language and the Body in Motion. Berlin, De Gruyter.

Haddington, P., Rauniomaa, M., 2014. Interaction between road users: Offering space in traffic. Space \& Culture 17 (2), 176-190.

Haun, D. B., Rapold, C. J., Janzen, G., Levinson, S. C., 2011. Plasticity of human spatial cognition: Spatial language and cognition covary across cultures. Cognition, 119 (1), 70-80.

Jensen, O. B., 2010. Erving Goffman and everyday life mobility. In: Jacobsen, M. H. (Ed.), The Contemporary Goffman. Abington, Routledge. 333-351.

Juhlin, O., 2010. Social Media on the Road: The Future of Car Based Computing. Berlin, Springer.

Katz, J., 1999. How Emotions Work. Chicago, University of Chicago Press.

Kendon, A., 1977. Spatial organization in social encounters: The F-formation system. In: Kendon, A. (Ed.), Studies in the Behavior of Social Interaction. Lisse, Peter DeRidder Press, pp. 179-208.

Lakoff, G., 1987. Women, Fire, and Dangerous Things: What Categories Reveal about the Mind. Chicago, University of Chicago Press.

Lakoff, G., Johnson, M., 1980. Metaphors We Live by. Chicago, University of Chicago Press.

Laurier, E., 2005. Searching for a parking space. Intellectica 41/42 (2/3), 101-116.

Laurier, E., this issue. Civility and mobility: Drivers (and passengers) appreciating the actions of other drivers.

Laurier, E., Brown, B., Lorimer, H., 2005. Habitable Cars: What We Do There. Edinburgh, Edinburgh Research Archive, www.era.lib.ed.ac.uk/handle/1842/815 (accessed 20 April 2018).

Laurier, E., Brown, B. Lorimer, H., 2012. What it means to change lanes: Actions, emotions and wayfinding in the family car. Semiotica 191 (1/4), 117-135.

Laurier, E., Brown, B., McGregor, M., 2015. Mediated pedestrian mobility: Walking and the map app. Mobilities 11 (1), 117-134.

Lee, J. R. E., Watson, R., 1992. Regards et habitudes des passants: les arrangements de visibilité de la locomotion. Les annales de la recherche urbaine 57/58, 101-109.

Levin, L., Cromdal, J., Broth, M., Gazin, A.-D., Haddington, P., McIlvenny, P., Melander, H., Rauniomaa, M., 2017. Unpacking corrections in mobile instruction: Error-occasioned learning opportunities in driving, cycling and aviation training. Linguistics and Education 38, 11-23.

Levinson, S. C., 2003. Space in Language and Cognition. Cambridge, Cambridge University Press. 
Liberman, K., 2013. The local orderliness of crossing Kincaid. In: Liberman, K. (Ed.), More Studies in Ethnomethodology. Albany, State University of New York Press, pp. 11-44.

Liberman, K., this issue. A study at $30^{\text {th }}$ street.

Licoppe, C., 2016. Mobilités et rencontres dans les espaces publics urbains à l'âge des médias positionnels. Réseaux 6 (200), 117-143.

McIlvenny, P., 2014. Vélomobile formations-in-action: Biking and talking together. Space \& Culture 17 (2), $137-156$.

McIlvenny, P., this issue. How did the mobility scooter cross the road? Coordinating with co-movers and other movers in traffic.

McIlvenny, P., Broth, M., Haddington, P., 2009. Communicating place, space and mobility. Journal of Pragmatics 41, 1879-1886.

McIlvenny, P., Broth, M., Haddington, P., 2014. Moving together: Mobile formations in interaction. Space \& Culture 17 (2), 104-106.

Merlino, S., Mondada, L., this issue. Crossing the street: How pedestrians interact with cars.

Mondada, L., 2002. La ville n'est pas peuplée d'être anonymes: processus de catégorisation et espace urbain. Marges linguistiques, 3. http://www.revue-texto.net/Parutions/Marges/00_ml052002.pdf (accessed 20 April 2018).

Mondada, L., 2012. Talking and driving: Multiactivity in the car. Semiotica 191 (1/4), 223-256.

Mondada, L., 2017. Walking and talking together: Questions/answers and mobile participation in guided visits. Social Science Information, 56 (2), 220-253.

Mondada, L., 2018. Multiple temporalities of language and body in interaction: Challenges for transcribing multimodality. Research on Language and Social Interaction 51 (1), 85-106.

Nevile, M., 2004. Beyond the Black Box: Talk-in-Interaction in the Airline Cockpit. Aldershot, Ashgate Press.

Nevile, M., 2007. Action in time: Ensuring timeliness for collaborative work in the airline cockpit. Language in Society 36 (2), 233-257.

Psathas, G., 1976. Mobility, orientation and navigation: Conceptual and theoretical considerations. New Outlook for the Blind, 70 (9), 385-391.

Psathas, G., 1992. The study of extended sequences: The case of the garden lesson. In: Watson, G., Seiler, R. M. (Eds.), Text in Context: Contributions to Ethnomethodology. London, Sage, pp. 99-122.

Pütz, M., Dirven, R. (Eds.), 1996. The Construal of Space in Language and Thought. Berlin, Mouton de Gruyter.

Rauniomaa, M., Haddington, P., Melander, H., Gazin, A-D., Broth, M., Cromdal, J., Levin, L., McIlvenny, P., 2018. Parsing tasks for the mobile novice in real time: Orientation to the learner's actions and to spatial and temporal constraints in instructing-on-the-move. Journal of Pragmatics 128, 30-52.

Relieu, M., 1994. Les catégories dans l'action: l'apprentissage de traversées de rue par des non-voyants. Raisons Pratiques 5, 185-218.

Relieu, M., 1999. Parler en marchant: pour une écologie dynamique des échanges de paroles. Langage et Société $89,37-67$.

Ryave, A. L., Schenkein, J. N., 1974. Notes on the art of walking. In: Turner, R. (Ed.), Ethnomethodology. Harmondsworth, Penguin, pp. 265-278.

Sacks, H., Schegloff, E. A., Jefferson, G., 1974. A simplest systematics for the organization of turn-taking for conversation. Language 50, 696-735.

Schegloff, E. A., 1972. Notes on a conversational practice: Formulating place. In: Sudnow, D. (Ed.), Studies in Social Interaction. New York, The Free Press, pp. 75-119.

Schmidt, J., 1872. Die Verwandtschaftsverhältnisse der indogermanischen Sprachen. Weimar, Hermann Böhlau. Senft, G., 1997. Referring to Space: Studies in Austronesian and Papuan Languages. Oxford, Clarendon Press.

Talmy, L., 2000. Toward a Cognitive Semantics. Cambridge MA, MIT Press.

Urry, J., 2004. The 'system' of automobility. Theory, Culture \& Society 21 (4/5), 25-39.

Urry, J., 2007. Mobilities. Oxford, Polity Press.

Vater, H., 1991. Einführung in die Raum-Linguistik. Hürth-Efferen, Gabel Verlag.

Vinkhuyzen, E., Cefkin, M., 2016. Developing socially acceptable autonomous vehicles. Ethnographic Praxis in Industry Conference Proceedings, 522-534.

von Savigny, E., 1980. Die Signalsprache der Autofahrer. München, dtv.

Watson, R., 2005. The visibility arrangements of public space: Conceptual resources and methodological issues in analysing movements. Communication \& Cognition 38 (1/2), 201-227.

Wegener, Ph., 1885. Untersuchungen über die Grundfragen des Sprachlebens. Halle, Max Niemeyer.

Elwys De Stefani* KU Leuven, Belgium

Mathias Broth 
Arnulf Deppermann

Institut für Deutsche Sprache, Mannheim, Germany

* Corresponding author. E-mail address: elwys.destefani@kuleuven.be 